\title{
Assessment of the Fatigue Behavior of Ti-6Al-4V ELI Alloy with Surface Treated by Nd:YAG Laser Irradiation
}

\author{
Fernanda Potomati ${ }^{,}$Leonardo Contri Campanelli ${ }^{a}{ }^{-}$, Paulo Sergio Carvalho Pereira da Silva ${ }^{a}$, \\ José Guilherme Alvarenga Batista Simões ${ }^{b}$, Milton Sergio Fernandes de Lima ${ }^{b}$, Álvaro José Damião ${ }^{b}$, \\ Claudemiro Bolfarini ${ }^{a}$
}

\author{
${ }^{a}$ Departamento de Engenharia de Materiais, Universidade Federal de São Carlos, Rodovia Washington Luiz, \\ Km 235, CEP 13565-905, São Carlos, SP, Brasil \\ ${ }^{b}$ Departamento de Ciência e Tecnologia Aeroespacial, Instituto de Estudos Avançados, Rodovia dos Tamoios, \\ Km 5,5, CEP 12228-970, São José dos Campos, SP, Brasil
}

Received: January 10, 2019; Revised: April 29, 2019; Accepted: June 02, 2019

\begin{abstract}
The effect of a surface treatment by Nd:YAG laser irradiation on the fatigue behavior of Ti-6Al-4V ELI was studied. Axial fatigue tests were performed to obtain S-N curves in polished and laser treated conditions. Roughness measurements and scanning electron microscopy were used to characterize the features of the modified surface. A reduction in the fatigue strength of around $35 \%$ was obtained after the laser treatment of the material surface. Although the surface roughness was in the micrometer scale, a notch effect was suggested to be the reason for the deleterious influence of the laser on the fatigue strength. The reduction in the fatigue strength obligatory demands redesign of implants for laser modified surfaces of Ti-6Al-4V alloy.
\end{abstract}

Keywords: Titanium, fatigue, laser, surface modification, roughness.

\section{Introduction}

In spite of the well-known benefits of Ti-6Al-4V alloy for biomedical applications, such as the modulus of elasticity, biocompatibility and corrosion resistance, the intrinsic bioinert surface necessarily requires some modification to change to a bioactive one. The idea is to enable the mechanical interbonding between the metallic surface irregularities and the bone porous without changing the properties of the substrate material ${ }^{1}$. The importance of this subject is such that many surface modification techniques have been studied so far, and proved to be efficient in improving the surface topography and consequently the biological performance of Ti implants. For instance, grit-blasting ${ }^{2}$, chemical etching ${ }^{3}$ and electrochemical treatment ${ }^{4}$, including the growth of nanotubes ${ }^{5}$, have provided suitable results. Studies have also shown that laser-based techniques are promising because macro, micro and nanoscale modifications are possible without undesirable contamination, since there is no direct contact with the substrate ${ }^{6}$. A high degree of precision is also an advantage over the other modification techniques ${ }^{7}$.

Recently, Lee et al. ${ }^{8}$ obtained promising results on the surface modification of pure Ti by a $\mathrm{Yb}: \mathrm{KGW}$ femtosecond laser. The surface of Ti-6Al-4V alloy was successfully treated by $\mathrm{Yu}$ et al. ${ }^{9}$ with a picosecond laser. To obtain a topography with a larger scale, Pou et al. ${ }^{6}$ employed both $\mathrm{CO}_{2}$ and Nd:YAG laser types over pure Ti.
The second type was found to present more promising results to modify the surface, because less splashes and more regular features were obtained. Nd:YAG irradiation was also applied to titanium screws and the surface was biomechanically assessed by Lee and Cho ${ }^{10}$, who stressed the potential of such surface treatment after obtaining good results on osseointegration and implant stability. Although Pou et al. ${ }^{6}$ mention in their paper the possibility of laser processing techniques to affect the mechanical properties of the substrate material, none of these recent works deal with mechanical tests.

Since it is well known that the fatigue performance is extremely sensitive to surface discontinuities, the present work aims to verify the influence of a laser treatment on the fatigue performance of the biomedical Ti-6Al-4V alloy in order to provide reliable data to the design of cyclic load bearing implants.

\section{Materials and Methods}

The material employed in this work was rounded bars of the commercial Ti-6Al-4V ELI alloy, in accordance with the requirements of ASTM F136 standard: typical equiaxed and refined $\alpha+\beta$ microstructure, as shown in Figure 1 . Cylindrical fatigue specimens were machined with geometry and dimensions following the ASTM E466 standard. All the specimens were grinded and polished up to a $1 \mu \mathrm{m}$ diamond abrasive. 


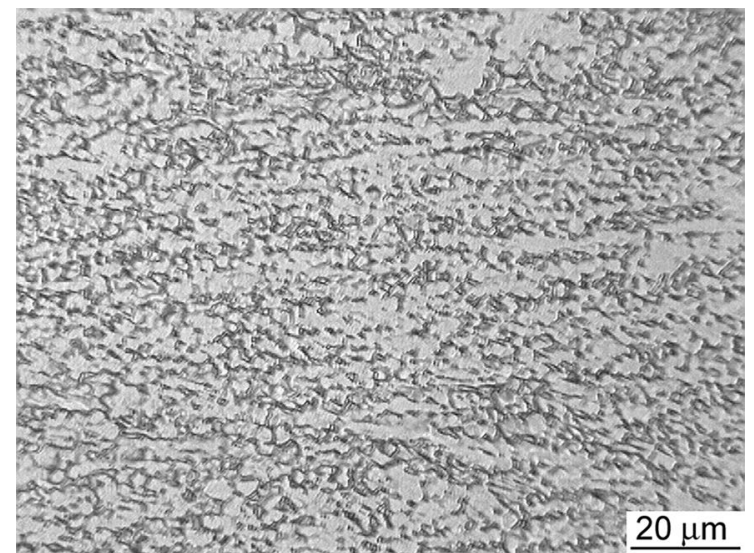

Figure 1. Microstructure of the received material.

Some of the polished specimens were irradiated with 104-nanosecond-laser pulses generated by a Q-switched Nd:YAG laser (Corona Coherent), in high power, operating with a spot size of $40 \mu \mathrm{m}$ and a wavelength of $1064 \mathrm{~nm}$. For the laser application, the cylindrical specimen was submitted to a rotational speed while the laser beam traveled at a longitudinal speed along the parallel reduced section. Figure 2 illustrates the specimen rotation and the laser beam path. The parameters for the laser treatment are summarized in Table 1.

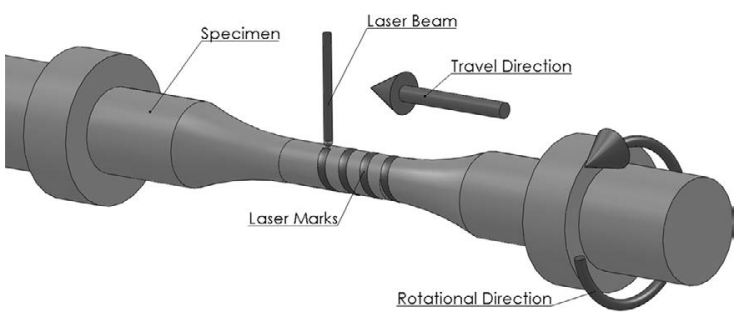

Figure 2. Illustration of the specimen rotation and laser beam path.
The modified surface was observed by scanning electron microscopy (SEM) using a FEI Quanta 400 FEG microscope. Confocal laser scanning microscopy (CLSM) with an Olympus Lext OLS 400 equipment was used for the roughness measurements. Table 2 brings the tensile mechanical properties of the polished and treated materials, showing that the laser treatment did not change those properties when considering the standard deviation values.

The axial fatigue tests of polished and laser treated specimens were carried out in air using an INSTRON 8872 servo hydraulic testing machine and the following parameters: $10 \mathrm{~Hz}$ frequency, stress ratio $\mathrm{R}=0.1$ and $5 \times 10^{6}$ cycles run-out. To build up the S-N curves, the fatigue tests were planned to use 4 or 5 load levels with at least 2 specimens at each level. Due to the scatter usually obtained in fatigue tests, a 95\% confidence band was calculated following the ASTM E739 standard and included in the S-N plots.

\section{Results}

The laser marks are formed by the combination of the specimen rotation and the forward movement of the laser beam, which resulted in spirals separated by smooth regions that were not reached by the laser. As shown in Figure 3, the beam path is characterized by the formation of fusion and ablation of the material. A certain asymmetry can be noticed in the mark: one side was more affected by the phenomenon of ablation and the surface became rougher, while the other side had a milder topography. The side that the ablation is more effective indicates the direction of the forward movement of the beam, i.e., in the images of Figure 3, the direction of the forward movement is towards the top of the images plane. The rotation direction is perceived by many impressions in shape of "half moons" left by the laser beam.

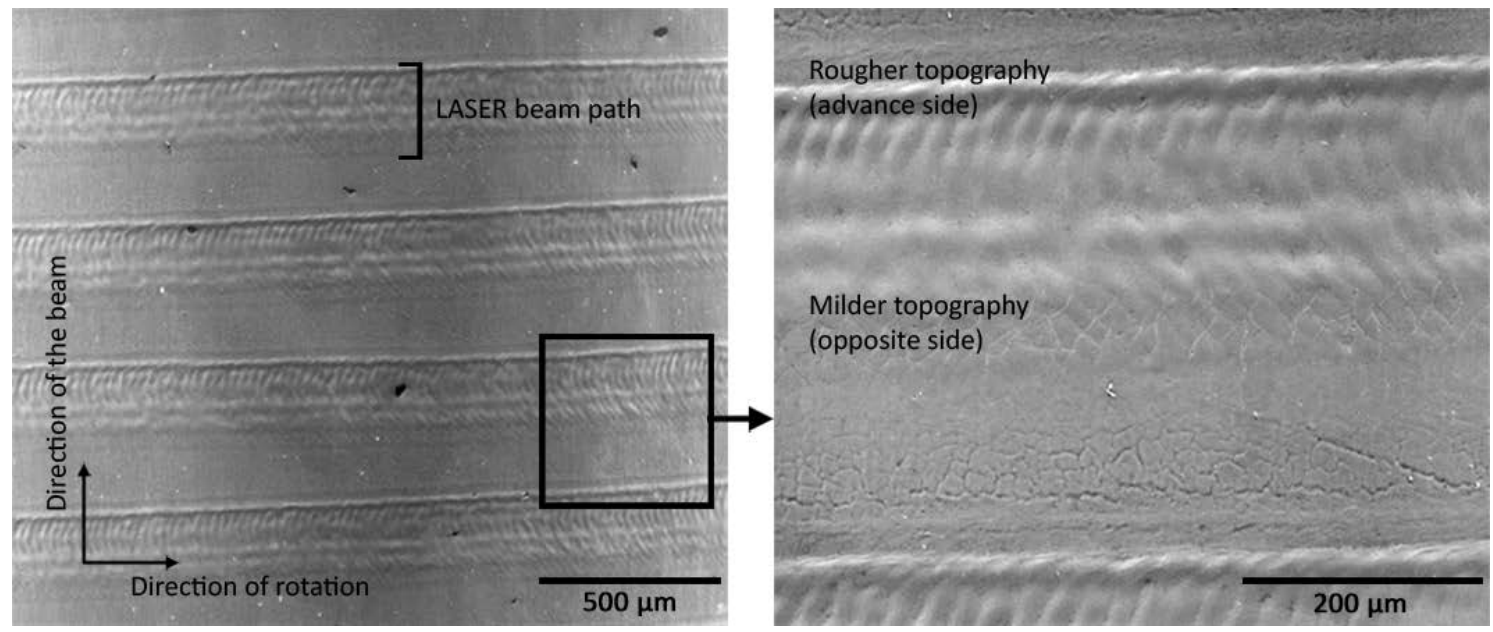

Figure 3. SEM micrographs with different magnifications of the surface modified by the laser treatment.

Table 1. Parameters employed in the laser treatment.

\begin{tabular}{ccccccc}
\hline Power $(\mathrm{W})$ & Intensity $\left(\mathrm{W} / \mathrm{cm}^{2}\right)$ & Fluence $\left(\mathrm{J} / \mathrm{cm}^{2}\right)$ & Frequency $(\mathrm{kHz})$ & Rotational speed $(\mathrm{rpm})$ & Longitudinal speed $(\mathrm{cm} / \mathrm{s})$ & Environment \\
\hline 22.5 & $3.44 \times 10^{9}$ & 358.0 & 5.0 & 600 & 0.4 & Argon \\
\hline
\end{tabular}


Table 2. Tensile mechanical properties of the studied material.

\begin{tabular}{lcccc}
\hline Condition & Yield strength $(\mathrm{MPa})$ & Ultimate strength $(\mathrm{MPa})$ & Elongation $(\%)$ & Modulus of elasticity $(\mathrm{GPa})$ \\
\hline ASTM F136 & $795 \mathrm{~min}$. & $860 \mathrm{~min}$. & $10 \mathrm{~min}$. & - \\
Polished & $959 \pm 7$ & $1007 \pm 3$ & $14 \pm 1$ & 110 \\
Laser & $931 \pm 31$ & $973 \pm 31$ & $17 \pm 2$ & 110 \\
\hline
\end{tabular}

When subjected to fatigue tests, the laser modified material presented a fatigue strength for $5 \times 10^{6}$ cycles of around 550 $\mathrm{MPa}$, as shown in the S-N curve in Figure 4. Compared to the polished material, which presented a fatigue strength of around $840 \mathrm{MPa}$, a considerable reduction of approximately $35 \%$ was observed after the laser treatment. The dotted lines comprise the $95 \%$ confidence band computed in accordance with the ASTM E739 standard. The fact that no intersection occurs between the bands indicates that the difference in the fatigue behavior of both conditions is statistically significant in the range of life assessed. The deleterious effect of the Nd:YAG laser on the fatigue response is therefore unquestionable when it is directly applied over the Ti substrate.

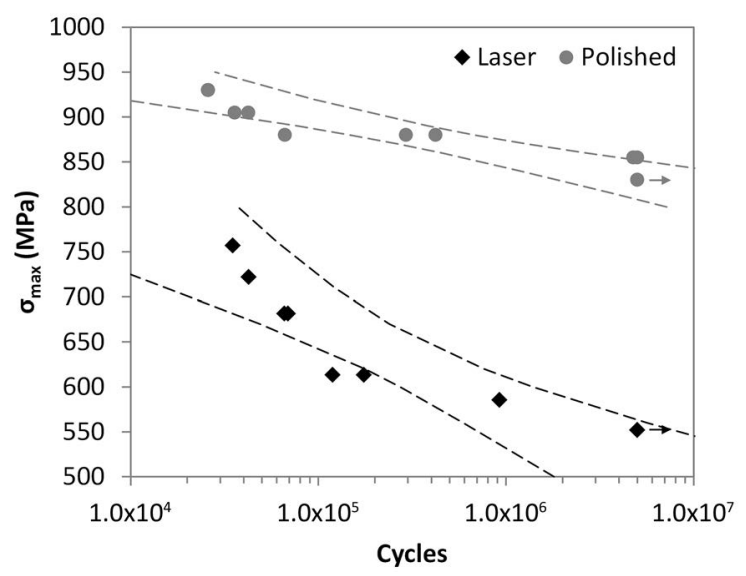

Figure 4. S-N curves for the polished and the surface modified by the laser treatment.

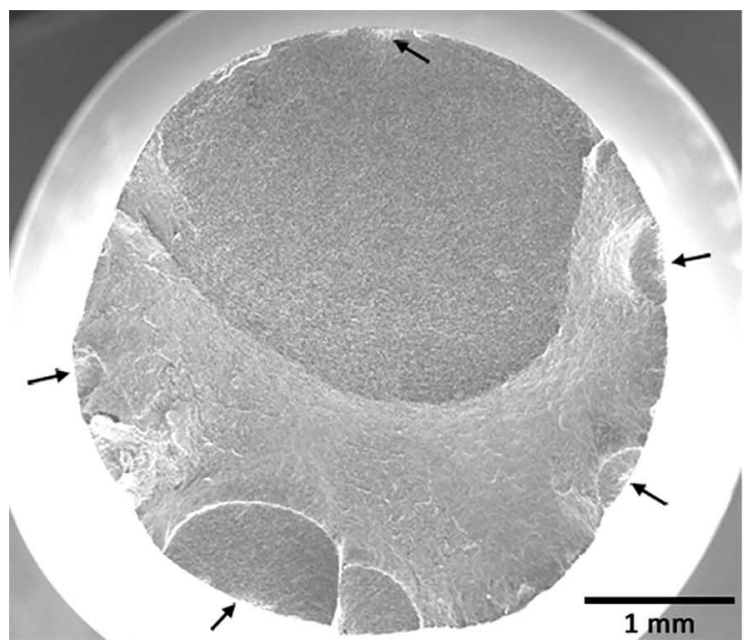

Table 3 presents the results of surface roughness. After the modification by laser, $R_{a}$ and $R_{z}$ were respectively increased to 2 and $13 \mu \mathrm{m}$, which suggest that a notch effect caused by the ablation phenomenon during the interaction substrate-laser may be responsible for the decrease of the fatigue strength.

The analysis of the fracture surface of the specimens that failed during the fatigue tests provided interesting information about the crack nucleation in relation to the topographic pattern left by the laser. As shown in Figure 5, multiple initiation sites occurred in the laser treated specimens, whereas a typical surface initiation in a single site was predominantly active in the polished specimens. It is interesting to note that the nucleation occurred both in the advance side of the laser beam, i.e. with a rougher topography, and in the opposite side of the beam path, where the ablation was milder. However, for all specimens that failed under fatigue, the cracks that propagated to final rupture were those nucleated in the advance side of the laser beam, probably due to the earlier nucleation. Crack propagation was similar in the laser treated and polished conditions, with a zone of stable propagation full of fatigue striations and a final zone of overload when the cross-section was reduced to the point that it could no longer support the load. In the laser treated condition, the multiple initiation sites resulted from the increased roughness, so that crack initiation was able to occur with lower values of stress, and the consequence was a lower fatigue strength.

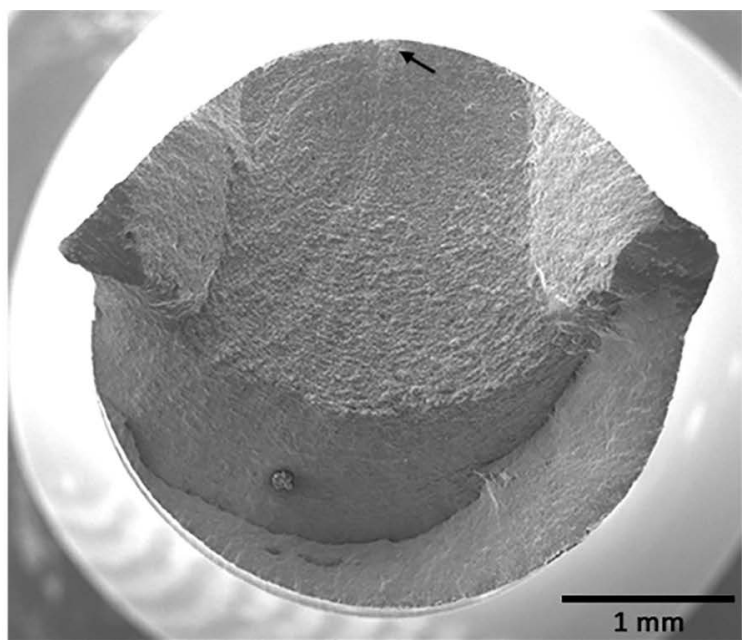

Figure 5. SEM micrographs of the fracture surface after fatigue tests: laser treated specimen in the left image and polished specimen in the right image. Each arrow indicates one crack nucleation site. 
Table 3. Results of roughness parameters.

\begin{tabular}{lcc}
\hline Surface & $\mathrm{Ra}(\mu \mathrm{m})$ & $\mathrm{Rz}(\mu \mathrm{m})$ \\
\hline Polished & $<0.1$ & $<0.1$ \\
Laser treated & $1.9 \pm 0.8$ & $12.9 \pm 2.7$ \\
\hline
\end{tabular}

\section{Discussion}

Da Silva et al. ${ }^{11}$ reported a prediction method for the fatigue limit $\left(\sigma_{f}\right)$ of Ti-6Al-4V ELI when it is correlated to a theoretical semi-circular notch described by the $\mathrm{R}_{\mathrm{z}}$ parameter. As reproduced in Figure 6, it is possible to predict that the fatigue strength for $\mathrm{R}_{\mathrm{z}}=13 \mu \mathrm{m}$ is $545 \mathrm{MPa}$. This value is in perfect agreement with the fatigue strength of around $550 \mathrm{MPa}$ observed in the S-N curve of the laser modified condition. It is noteworthy that the prediction method does not consider microstructural effects, and, since a very reliable prediction was obtained, it is possible to conclude that any microstructural alteration that could result from the laser treatment had a negligible influence when compared to the effect of the notches.

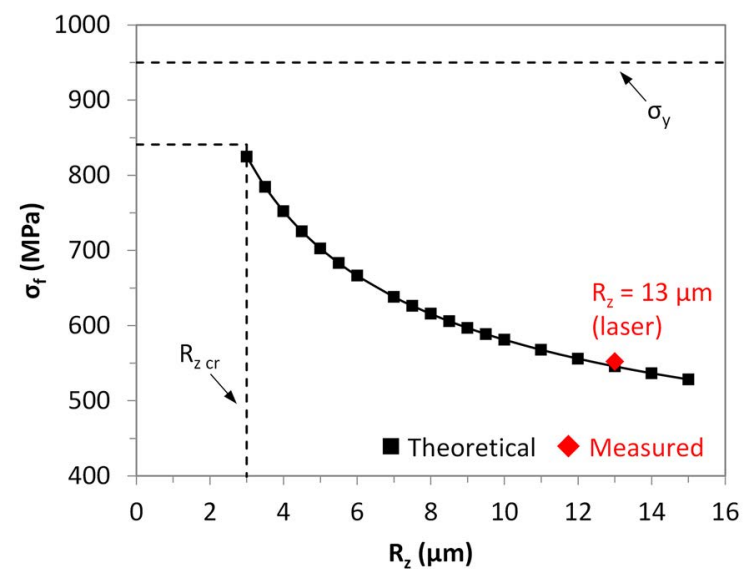

Figure 6. Curve of fatigue limit $(\sigma f)$ in function of roughness [11]. The result of the present work was indicated as "measured".

Table 4 brings some recent results on the fatigue performance of Ti-6Al-4V ELI with different surface modifications, but focused on the improvement of the biomechanical bone-material adhesion. It is important to mention that these fatigue data were all obtained using exactly the same experimental conditions, such as axial loading, stress ratio $\mathrm{R}=0.1$ and frequency in the range of $5-20 \mathrm{~Hz}$. Micro-arc oxidation ${ }^{12}$ and chemical etching ${ }^{3}$ produced modified layers with $R_{z}$ value smaller than the critical $R_{z}$ in the curve of Figure 5, and therefore the fatigue strength was not affected by the surface modification. In the case of the nanotubes, although $\mathrm{R}_{\mathrm{z}}$ value was not reported, the modified layer was found to have a thickness of $0.6 \mu \mathrm{m}$ ${ }^{13}$, which is also below a critical notch size. On the other hand, in the conditions employed in the present work, the $\mathrm{Nd}$ :YAG laser resulted in a topography with notches in a scale on the order of few microns that strongly affected the fatigue performance of the material.

This reduction in the fatigue strength of the laser modified surface of the Ti-6Al-4V alloy is of concern for the design of stems for hip arthroplasty. Several authors reported principal stresses above $500 \mathrm{MPa}$ in critical points of such stems ${ }^{14,15}$, which comprises a value that could lead to premature fatigue fractures of implants subjected to $\mathrm{Nd}$ :YAG laser treatment. For instance, it was performed a stress simulation in a commercial stem for revision surgery for old patients and the results can be seen in Figure $7^{16}$.

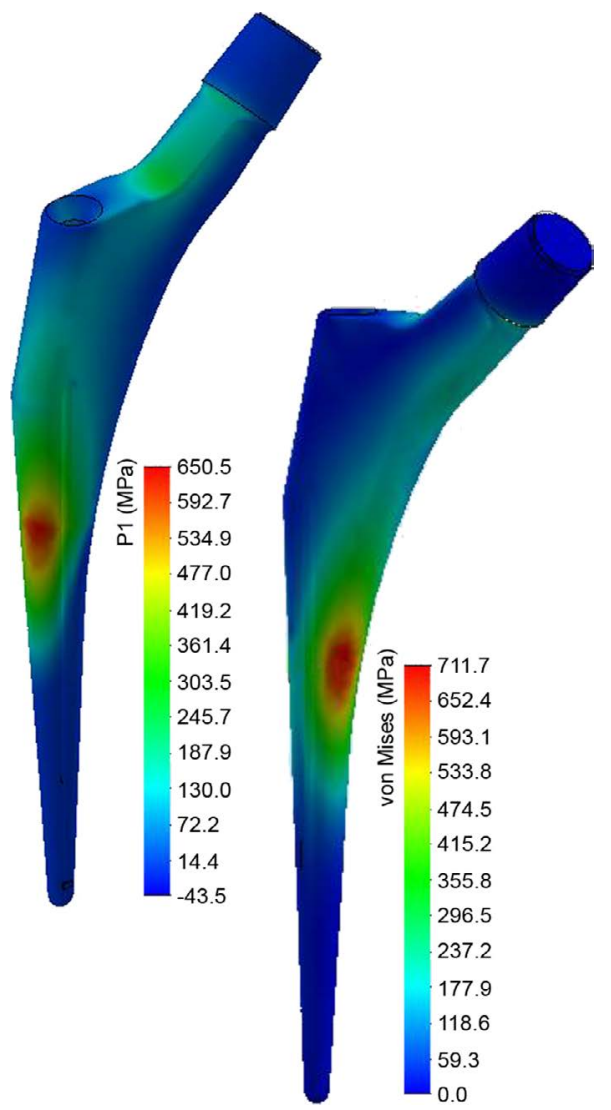

Figure 7. Distribution of the first principal and von Mises stresses in a commercial femoral stem. Part of it published in [16].

Table 4. Comparison of different surface modification techniques on Ti-6Al-4V ELI.

\begin{tabular}{lccc}
\hline Treatment & $\mathrm{R}_{\mathrm{z}}(\mu \mathrm{m})$ & Fatigue & Reference \\
\hline Nd:YAG laser & 12.9 & Strong reduction & Present work \\
Micro-arc oxidation & 0.4 & Unchanged & Potomati et al. [12] \\
$\mathrm{HCl}+\mathrm{NaOH}$ etching & 2.0 & Unchanged & Escobar Claros et al. [3] \\
$\mathrm{TiO}_{2}$ nanotubes & - & Unchanged & Campanelli et al. [13] \\
\hline
\end{tabular}


The boundary conditions and the methodology are published elsewhere ${ }^{17}$. The calculations show that values in the range of $400 \mathrm{MPa}$ to $650 \mathrm{MPa}$ can be obtained in critical parts of the stem and would induce fatigue cracks before the limit of $5 \times 10^{6}$ cycles established by the biomedical standards for such components. Thus, redesigns of the stems are demanded if the present laser modification is to be used for improving the osseointegration. Other types of laser necessarily require fatigue assessment.

\section{Conclusions}

The surface modification of Ti-6Al-4V ELI alloy by $\mathrm{Nd}$ :YAG laser for biomedical purpose led to an increase in roughness, with $\mathrm{R}_{\mathrm{a}}$ and $\mathrm{R}_{\mathrm{z}}$ values of respectively $2 \mu \mathrm{m}$ and $13 \mu \mathrm{m}$. Due to a notch effect, the fatigue strength was severely affected after the surface modification, decreasing from $840 \mathrm{MPa}$ in the polished surface to $550 \mathrm{MPa}$ at $5 \times 10^{6}$ cycles. The results were in satisfactory agreement with the prediction curve that correlates the fatigue limit and the $\mathrm{R}_{\mathrm{z}}$ roughness parameter. In case of using such surface modification, redesign of implants is mandatory in order to avoid premature failure by fatigue.

\section{Acknowledgements}

The authors acknowledge the following Brazilian institutions for the financial support: National Council for Scientific and Technological Development (CNPq) and The São Paulo Research Foundation (FAPESP - process n. 2016/12995-5).

\section{References}

1. Fernandes DJ, Marques RG, Elias CN. Influence of acid treatment on surface properties and in vivo performance of Ti6Al4V alloy for biomedical applications. Journal of Materials Science. Materials in Medicine. 2017;28(10):164.

2. Leinenbach C, Schwilling B, Eifler D. Cyclic deformation behaviour and fatigue induced surface damage of titanium alloys in simulated physiological media. Materials Science and Engineering: C. 2005;25(3):321-329.

3. Escobar Claros CA, Oliveira DP, Campanelli LC, da Silva PSCP, Bolfarini C. Fatigue behavior of Ti-6Al-4V alloy in saline solution with the surface modified at a micro- and nanoscale by chemical treatment. Materials Science and Engineering: C. 2016;67:425-432.

4. Campanelli LC, Duarte LT, da Silva PSCP, Bolfarini C. Fatigue behavior of modified surface of Ti-6Al-7Nb and CP-Ti by micro-arc oxidation. Materials \& Design. 2014;64:393-399.
5. Bortolan CC, Campanelli LC, Bolfarini C, Oliveira NTC. Fatigue strength of Ti-6Al-4V alloy with surface modified by $\mathrm{TiO}_{2}$ nanotubes formation. Materials Letters. 2016;177:46-49.

6. Pou P, Riveiro A, del Val J, Comesaña R, Penide J, Arias-González $\mathrm{F}$, et al. Laser surface texturing of Titanium for bioengineering applications. Procedia Manufacturing. 2017;13:694-701.

7. Kurella A, Dahotre NB. Review paper: Surface Modification for Bioimplants: The Role of Laser Surface Engineering. Journal of Biomaterials Applications. 2005;20(1):5-50.

8. Lee BEJ, Exir H, Weck A, Grandfield K. Characterization and evaluation of femtosecond laser-induced sub-micron periodic structures generated on titanium to improve osseointegration of implants. Applied Surface Science. 2018;441:1034-1042.

9. Yu Z, Yang G, Zhang W, Hu J. Investigating the effect of picosecond laser texturing on microstructure and biofunctionalization of titanium alloy. Journal of Materials Processing Technology. 2018;255:129-136.

10. Lee JT, Cho SA. Biomechanical evaluation of laser-etched Ti implant surfaces vs. chemically modified SLA Ti implant surfaces: Removal torque and resonance frequency analysis in rabbit tibias. Journal of the Mechanical Behavior of Biomedical Materials. 2016;61:299-307.

11. da Silva PSCP, Campanelli LC, Escobar Claros CA, Ferreira T, Oliveira DP, Bolfarini C. Prediction of the surface finishing roughness effect on the fatigue resistance of Ti-6Al-4V ELI for implants applications. International Journal of Fatigue. 2017;103:258-263.

12. Potomati F, Giordani EJ, Duarte LT, de Alcântara NG, Bolfarini C. Fatigue behavior and physical characterization of surfacemodified Ti-6Al-4V ELI alloy by micro-arc oxidation. Materials Research. 2012;15(2):305-311.

13. Campanelli LC, Bortolan CC, da Silva PSCP, Bolfarini C, Oliveira NTC. Effect of an amorphous titania nanotubes coating on the fatigue and corrosion behaviors of the biomedical Ti-6Al-4V and Ti-6Al-7Nb alloys. Journal of the Mechanical Behavior of Biomedical Materials. 2017;65:542-551.

14. Ploeg HL, Bürgi M, Wyss UP. Hip stem fatigue test prediction. International Journal of Fatigue. 2009;31(5):894-905.

15. Campioni I, Notarangelo G, Andreaus U, Ventura A, Giacomozzi C. Hip Prostheses Computational Modeling: FEM Simulations Integrated with Fatigue Mechanical Tests. In: Iacoviello D, Andreaus U, eds. Biomedical Imaging and Computational Modeling in Biomechanics. Lecture Notes in Computational Vision and Biomechanics 4. Dordrecht: Springer; 2013.p. 81-108.

16. Bolfarini C, Campanelli LC, Guerra APB. Fatigue performance of a Ti-6Al-4V femoral prosthesis modified by thermal plasma spray. In: $10^{\text {th }}$ World Biomaterials Congress; 2016 May 17-22; Montreal, Canada.

17. de Oliveira BJS, Campanelli LC, Oliveira DP, Guerra APB, Bolfarini C. Surface characterization and fatigue performance of a chemical-etched Ti-6Al-4V femoral stem for cementless hip arthroplasty. Surface and Coatings Technology. 2017;309:1126-1134. 